Research Paper

\title{
U-series dating of carbonates using inductively coupled plasma-quadrupole mass spectrometry
}

\author{
E. Hernández-Mendiola ${ }^{\mathrm{a}, 1}$, J.P. Bernal ${ }^{\mathrm{b}, \mathrm{c}, *}$, E. Lounejeva ${ }^{\mathrm{b}}$, G.E. Mortimer ${ }^{\mathrm{d}}$, M.T. McCulloch ${ }^{\mathrm{e}}$ \\ a Posgrado en Ciencias de la Tierra, Universidad Nacional Autónoma de México, Ciudad Universitaria, Coyoacán, 04510 Mexico City, Mexico \\ ${ }^{\mathrm{b}}$ Instituto de Geología, Universidad Nacional Autónoma de México, Ciudad Universitaria, Coyoacán, 04510 Mexico City, Mexico \\ ${ }^{\mathrm{c}}$ Centro de Geociencias, Universidad Nacional Autónoma de México, Campus Juriquilla, Juriquilla, Querétaro 76230, Mexico \\ ${ }^{\mathrm{d}}$ Research School of Earth Sciences, The Australian National University, Canberra, ACT 0200, Australia \\ e Oceans Institute, School of Earth and Environment and ARC Centre of Excellence in Coral Reef Studies, The University of Western Australia, Crawley, WA 6009, Australia
}

\section{A R T I C L E I N F O}

\section{Article history:}

Received 12 January 2011

Received in revised form

30 August 2011

Accepted 1 September 2011

Available online 10 September 2011

\section{Keywords:}

U-series dating

ICP-QMS

Corals

Speleothems

\begin{abstract}
A B S T R A C T
We describe an analytical methodology to quantify ${ }^{238} \mathrm{U}-{ }^{234} \mathrm{U}$ and ${ }^{230} \mathrm{Th}$ using isotope-dilution systematics and inductively coupled plasma-quadrupole mass spectrometry (ICP-QMS) for geochronological purposes. This required characterization of the mass spectrometer detector performance over a large dynamic range, including a careful calibration between pulse and analogue ion-counting modes. Our methodology gives an analytical precision for ${ }^{234} \mathrm{U} /{ }^{238} \mathrm{U}$ and ${ }^{230} \mathrm{Th} /{ }^{238} \mathrm{U}$ of $4 \%$ and $7 \%$ o $(2 \times$ standard error), respectively, and yields ${ }^{230} \mathrm{Th}$-ages with $4-5 \%$ uncertainty from $500 \mathrm{ng}$ of ${ }^{238} \mathrm{U}$. We tested our methodology by analyzing carbonate samples (corals and speleothems) which were previously dated using MC-ICPMS; excellent agreement between both techniques was obtained. Our results indicate that ICP-QMS is suitable to obtain valuable meaningful geochronological data, but it is limited to dating samples older than $1 \mathrm{ka}$, and younger than $400 \mathrm{ka}$. Our methodology thus represents an attractive alternative to obtain geochonological data to select the most interesting samples prior to high-precision analysis. Moreover, such data would also valuable to build preliminary age-models, which can be further complemented with high-precision analyses.
\end{abstract}

(C) 2011 Elsevier B.V. All rights reserved.

\section{Introduction}

U-Th geochronology is one of the most powerful tools for unraveling the complex geological and climatic history of the Earth during the late Quaternary; the use of $U$ and Th-isotope composition as proxies for a wide range of geological and environmental processes also makes them an essential tool for modern geochemical studies (Bourdon et al., 2003). Despite this, only a few laboratories worldwide have this capability, primarily because of the extremely low ${ }^{234} \mathrm{U} /{ }^{238} \mathrm{U}$ and ${ }^{230} \mathrm{Th} /{ }^{238} \mathrm{U}$ ratios, the inherent difficulty of detecting the low-abundance isotopes ${ }^{234} \mathrm{U}$ and ${ }^{230} \mathrm{Th}$ in the presence of high-abundance ${ }^{238} \mathrm{U}$, and the scarcity of highpurity spikes, particularly ${ }^{229} \mathrm{Th}$, required for the precise and accurate determination of ${ }^{234} \mathrm{U} /{ }^{238} \mathrm{U}$ and ${ }^{230} \mathrm{Th} /{ }^{238} \mathrm{U}$ by isotopedilution.

\footnotetext{
* Corresponding author. Centro de Geociencias, Universidad Nacional Autónoma de México, Campus Juriquilla, Juriquilla, Querétaro 76230, Mexico. Tel.: +52 442 $2381104 \times 137$.

E-mail address: jpbernal@geociencias.unam.mx (J.P. Bernal).

1 Present address: Centro Nacional de Investigación y Capacitación Ambiental, Periférico 5000, Col. Insurgentes Cuicuilco, CP 04530 Mexico City, Mexico.
}

Because of the low activity of ${ }^{234} \mathrm{U}$ and ${ }^{230} \mathrm{Th}$, uncertainties of several \% are typically obtained during the U-Th dating of carbonates by $\alpha$-spectrometry (Goldstein and Stirling, 2003). Such uncertainties, along with the large amount of sample required, were significantly diminished after the introduction of magneticsector mass-spectrometric methods in the 1980's (Chen et al., 1986; Edwards et al., 1987); since then, further advances in massspectrometry technology have improved detection limits and precision by enhancing ion-production (Houk et al., 1980), increasing detector sensitivity, reducing or controlling the sources of background (Hunter, 1994), and increasing signal stability (Bradshaw, 1989). These, along with improvements in $U$ and Th purification methods, make possible sub-permil precision and $\mathrm{fg} / \mathrm{g}$ or pg/g detection limits (Andersen et al., 2004; Potter et al., 2005a), allowing the detection of small deviations from secular equilibrium in very old samples (Andersen et al., 2008), or quantification of extremely small amounts of ${ }^{230} \mathrm{Th}$ in very young samples (McCulloch and Mortimer, 2008; Shen et al., 2008; Zhao et al., 2009). Moreover, the ability to measure instrumental mass bias for Th isotopes has also enhanced the accuracy of U-series dating (Hoffmann et al., 2007; Hoffmann, 2008). Unfortunately, the high- 
precision instrumentation required for such measurements is not always available. Here we explore the feasibility of using the widely available inductively coupled plasma-quadrupole mass spectrometry (ICPM-QMS) coupled with a high-efficiency sample introduction system (APEX-Q). We show that this provides an alternative to high-precision instrumentation to quantify ${ }^{234} \mathrm{U}$ and ${ }^{230} \mathrm{Th}$ in carbonates by isotope-dilution for ${ }^{234} \mathrm{U}-{ }^{230} \mathrm{Th}$ geochronological purposes.

Modern ICP-QMS is an attractive, low-cost, and widely available alternative to high-precision instrumentation. It is characterized by detection limits of only few $\mathrm{pg} / \mathrm{g}$, which can be improved $\sim 10 \times$ by using an efficient sample introduction system, such as a desolvators. Moreover, isotope-ratio measurements with sub-permil precision can be achieved in the most ideal cases (Bandura et al., 2000; De Muynck et al., 2008). In conjunction with laser ablation, ICP-QMS is commonly used for $\mathrm{U}-\mathrm{Pb}$ dating of zircons and other accessory igneous mineral phases, with age uncertainties of only 2-4\%(Horn et al., 2000; Kosler et al., 2002; Black et al., 2004; Solari et al., 2010). ICP-QMS has also been demonstrated to be useful for $\mathrm{Rb}-\mathrm{Sr}$ geochronology (Vanhaecke et al., 2003), although few applications have followed suit. Moreover, most ICP-QMS are equipped with long-dynamic range electron multipliers suitable for measuring very low isotope ratios $\left(<10^{-4}\right)$, such as ${ }^{234} \mathrm{U} /{ }^{238} \mathrm{U}$ and ${ }^{230} \mathrm{Th} /{ }^{238} \mathrm{U}$.

The feasibility of measuring U-isotopic compositions using ICPQMS, including ${ }^{234} \mathrm{U} /{ }^{238} \mathrm{U}$, has been previously demonstrated (Shaw and Francois, 1991; Mas et al., 2006) and per-mil precision can be achieved (Shen et al., 2006). Recently, deviations from secular equilibrium have been successfully measured in ancient carbonates with the aim of age-scan samples prior to high-precision U-series dating (Douville et al., 2010). Alternative methodologies for agescanning have been proposed earlier (Potter et al., 2005b; McGregor et al., 2011). These are based on laser-ablation microsampling and, in addition to the requirement of very specialized instrumentation, significant method optimization prior to sample analysis is required. Moreover, the lack of a geological certified standards for microanalyis with known ${ }^{234} \mathrm{U} /{ }^{238} \mathrm{U}$ and ${ }^{230} \mathrm{Th} /{ }^{238} \mathrm{U}$ is a significant conundrum that needs to be solved, usually via extensive spatial and isotopic characterization (e.g. Bernal et al., 2005), prior to routine age-scan analysis, otherwise, complex and uncharacterized matrix effects can potentially lead to incorrect geochronological conclusions. The methodology presented here is based on the same principles as the most precise methods (Luo et al., 1997; Hellstrom, 2003; Fietzke et al., 2005; McCulloch and Mortimer, 2008; Shen et al., 2008), and full implementation is possible after some instrumental characterization.

The methodology presented here required us to carefully characterize the response of the detector over its dynamic range, and developed a methodology to fully correct for the small differences in detector efficiencies between the different sections (pulsecounting and analogue). This has allowed us to determine ${ }^{234} \mathrm{U} /{ }^{238} \mathrm{U}$ and ${ }^{230} \mathrm{Th} /{ }^{238} \mathrm{U}$ with uncertainties of $4 \%$ and $7 \%$ $(2 \times$ standard error, $2 \mathrm{E})$, respectively, from $\sim 500 \mathrm{ng} \mathrm{U}$ aliquots, which translates into 3-5\% age uncertainties for samples older than $1 \mathrm{ka}$. We assess the accuracy of our methodology by analyzing secular equilibrium standards, as well as coral and speleothem samples previously dated by MC-ICPMS.

\section{Experimental}

\subsection{Standards, reagents and ${ }^{229}$ Th and ${ }^{233} U$ tracers}

All samples and solutions were prepared and stored in PTFE vessels in a Class 100 laboratory under laminar-flow hoods, using triple-distilled acids diluted in Milli-Q water (18.2 M $\Omega$ ). Procedural blanks were always $\leq 12 \mathrm{pg} / \mathrm{g}$ of ${ }^{238} \mathrm{U}$ and $<1 \mathrm{pg} / \mathrm{g}$ for ${ }^{232} \mathrm{Th}$ and ${ }^{230} \mathrm{Th}$, thus corrections by blank contributions were not necessary. A solution of the U isotopic standard NIST SRM 960 was prepared from $U$ metal. This was previously cleaned in Milli-Q water, 1:1 $\mathrm{HNO}_{3}, 1: 3 \mathrm{HCl}$, thoroughly rinsed in Milli-Q water, and vacuum dried in a desiccator at room temperature (Cali, 1972). Once cleaned and dried, the material was dissolved in $1: 1 \mathrm{HNO}_{3}$ and gravimetrically diluted to obtain a $10 \mathrm{mg} / \mathrm{g}$ U stock solution, from which further dilutions were prepared as required. This standard is certified for a ${ }^{238} U /{ }^{235} U$ composition of 137.88 (Cali, 1972), but recent and more precise measurements have concluded that such value is between $0.03 \%$ (Richter et al., 2010) and 0.08\% (Condon et al., 2010) lower than the certified composition. Although this material is not certified for its ${ }^{234} \mathrm{U} /{ }^{238} \mathrm{U}$ composition, analysis by several laboratories using MC-ICPMS and TIMS yield $a^{234} U /{ }^{238} U=(52.86 \pm 0.021) \times 10^{-6}$ (robust mean from Andersen et al., 2004), equivalent to $\delta^{234} U=-36.87 \pm 0.40 \%$ o $(n=17$, MSWD 0.54 , probability 0.93 ), which is in agreement with the recently published value by Richter et al. (2010).

The $U$ and Th isotopes were quantified using normal isotopedilution systematics. Samples were spiked with known amounts of ${ }^{233} \mathrm{U}$ and ${ }^{229} \mathrm{Th}$ acquired from Isotrak (AEA Technology QSA Inc, UK). The spikes were calibrated for their isotopic composition by measuring three different aliquots bracketed by SRM 960 to correct for mass bias using ${ }^{238} \mathrm{U} /{ }^{235} \mathrm{U}=137.88$. The resulting isotopic composition for each spike is summarized in Table 2, and shows good agreement with the available data from the certificate provided by AEA Technology. We note that use of the recently published improved values of ${ }^{238} \mathrm{U} /{ }^{235} \mathrm{U}$ for SRM 960 (Condon et al., 2010; Richter et al., 2010) represent only a small change $(<0.1 \%)$ in the calculated isotopic compositions and ages presented here, and well within the uncertainty of our measurements. Because of the relatively low-purity of our ${ }^{229} \mathrm{Th}$ tracer $\left({ }^{229} \mathrm{Th} /{ }^{230} \mathrm{Th}=650 \pm 21\right.$, see below), its concentration in the spiked sample was kept as low as possible to minimize its contribution upon the total ${ }^{230} \mathrm{Th}$; resulting in ${ }^{239} \mathrm{Th}_{\text {spike }}{ }^{230} \mathrm{Th}_{\text {sample lower than } 250 .}$

To assess the precision and accuracy of our measurements, we prepared solutions from Harwell uraninite (HU-1), which is known to be in secular equilibrium with respect to ${ }^{234} \mathrm{U} /{ }^{238} \mathrm{U}=(54.875$ $\pm 0.003) \times 10^{-6}$ (robust mean from data summarized in Andersen

Table 1

Summary of relevant instrumental parameters used in this work.

\begin{tabular}{ll}
\hline Forward power & $1450 \mathrm{~W}$ \\
Carrier gas & $0.7 \mathrm{~min}^{-1}$ \\
Make-up gas & $0.31 \mathrm{~min}^{-1}$ \\
Sample uptake & $400 \mu \mathrm{min}^{-1}$ \\
Extraction voltage 1 & $2.1 \mathrm{~V}$ \\
Extraction voltage 2 & $143 \mathrm{~V}$ \\
Omega-bias & $-18 \mathrm{~V}$ \\
Omega lens & $2.4 \mathrm{~V}$ \\
Detector voltages & \\
Pulse counting & $1660 \mathrm{~V}$ \\
Analogue & $1300 \mathrm{~V}$ \\
Discriminator (factory setting) & $4 \mathrm{mV}$ \\
Dwell time (s): & \\
${ }^{238} \mathrm{U}$ & 0.7 \\
${ }^{235} \mathrm{U}$, & 0.85 \\
${ }^{234} \mathrm{U}$, & 1.1 \\
${ }^{233} \mathrm{U}$, & 0.3 \\
${ }^{232} \mathrm{Th}$ & 0.2 \\
${ }^{230} \mathrm{Th}$, & 1.0 \\
${ }^{229} \mathrm{Th}$ & 0.85 \\
Settling time & 0.001 \\
$\mathrm{APEX}$ & \\
Heating & $120{ }^{\circ} \mathrm{C}$ \\
$\mathrm{Cooling}_{\mathrm{N}}$ & $2{ }^{\circ} \mathrm{C}$ \\
$\mathrm{N}_{2}$ added. & \\
\hline
\end{tabular}


Table 2

Isotopic compositions of the U-3 and T-9 spikes used in this work. For all cases the error weighted mean is the result form 3 independent analyses of U-3 and 4 independent analysis of T-9. Uncertainties correspond to \pm 1 SE. Expected values correspond to specifications from Isotrak product UBP 10010 certificate obtained by alpha spectrometry.

\begin{tabular}{|c|c|c|c|c|}
\hline & ${ }^{233} U$ & ${ }^{234} \mathrm{U}$ & ${ }^{235} \mathrm{U}$ & ${ }^{238} \mathrm{U}$ \\
\hline$\% \mathrm{w} / \mathrm{w}$ & $99.658 \pm 0.008$ & $0.240 \pm 0.005$ & $0.020 \pm 0.001 \%$ & $0.090 \pm 0.004 \%$ \\
\hline Expected & 99.7 & 0.24 & 0.02 & 0.07 \\
\hline${ }^{233} \mathrm{U} /{ }^{\mathrm{n}} \mathrm{U}$ & - & $418 \pm 6$ & $6038 \pm 46$ & $1092 \pm 43$ \\
\hline & \multicolumn{2}{|c|}{${ }^{229} \mathrm{Th}$} & ${ }^{230} \mathrm{Th}$ & ${ }^{232} \mathrm{Th}$ \\
\hline $\begin{array}{l}\% \mathrm{w} / \mathrm{w} \\
{ }^{229} \mathrm{Th} /{ }^{\mathrm{n}} \mathrm{Th}\end{array}$ & \multicolumn{2}{|c|}{$99.01 \pm 0.02$} & $\begin{array}{l}0.150 \pm 0.005 \\
650 \pm 21\end{array}$ & $\begin{array}{l}0.84 \pm 0.02 \\
117 \pm 2\end{array}$ \\
\hline
\end{tabular}

et al., 2004) and very close to secular equilibrium with respect to ${ }^{230} \mathrm{Th} /{ }^{238} \mathrm{U}=(16.995 \pm 0.0028) \times 10^{-6}$ (Cheng et al., 2000). These solutions allowed us to verify the concentration of our ${ }^{229} \mathrm{Th}$ spike.

\subsection{Samples and sample preparation}

Six coral samples were analyzed with our methodology; these correspond to exposed fossil coral reef specimens of Acropora palmata from the Yucatán Peninsula, which have been interpreted to reflect a marine high-stand during the last interglacial (Blanchon et al., 2009). Their U-concentration ranges between 2.5 and $3.5 \mu \mathrm{g} / \mathrm{g}$, with measured $\delta^{234} \mathrm{U}^{2}$ ranging between 144 and $172 \%$; ${ }^{232} \mathrm{Th}$ is below $0.5 \mathrm{ng} / \mathrm{g}$, thus corrections for the detrital contributions are negligible. The samples were previously dated by MCICPMS at the Leibniz Institute of Marine Sciences (GEOMAR), using multi-static, multi-ion counting methodologies detailed in Fietzke et al. (2005).

The samples were dissolved with concentrated $\mathrm{HNO}_{3}$ in PTFE vessels and spiked with ${ }^{233} \mathrm{U}$ and ${ }^{229} \mathrm{Th}$. The dissolved coral samples were treated with $\mathrm{H}_{2} \mathrm{O}_{2}$ to decompose organic matter. $\mathrm{U}$ and Th were separated by extraction chromatography using the TRU resin (Eichrom Technologies, Inc) following the procedures by Luo et al. (1997); however, Th was eluted using $\mathrm{HCl} 0.5 \mathrm{M}$ in order to attain a better separation between $U$ and Th (Howritz et al., 1993). Under this conditions, $>97 \%$ of total Th is consistently leached from the resin, whilst $>99 \% \mathrm{U}$ remains in the column, which is then eluted with a $0.1 \mathrm{M} \mathrm{HCl} / \mathrm{HF}$ mixture; $\mathrm{U}$ and $\mathrm{Th}$ recoveries were always $>95 \%$. In order to reduce any potential spectral interference by non-digested organic material eluted from the resin (Pietruszka et al., 2002; McCulloch and Mortimer, 2008), a pre-filter material consisting on nonfunctionalized resin support (also supplied by Eichrom) was introduced to the column underneath the resin, to adsorb such organic material.

In addition to the coral samples, two stalagmites previously dated by MC-ICPMS at the Australian National University (ANU) were analyzed to compare the performance of our methodology. A detailed description of the methodology used at the ANU is described in McCulloch and Mortimer (2008). The stalagmites, COYO-01 and COYO-04 were collected from Coyozochico Cave in Cuetzalan, México, and are characterized for their relatively high Ucontent $(\sim 8 \mu \mathrm{g} / \mathrm{g})$, and very low detrital contamination, with $\left[{ }^{230} \mathrm{Th} /{ }^{232} \mathrm{Th}\right]>1000$, hence corrections for the presence of ${ }^{230} \mathrm{Th}_{\text {detrital }}$ are negligible (Hernández-Mendiola et al., 2007). For each stalagmite, a basic age-model was constructed based upon the MC-ICPMS ages by linearly interpolating between each dated site.

\footnotetext{
${ }^{2}$ Where $\delta^{234} \mathrm{U}=\left(\left(\left({ }^{234} \mathrm{U} /{ }^{238} \mathrm{U}\right)_{\text {sample }} /\left({ }^{234} \mathrm{U} /{ }^{238} \mathrm{U}\right)_{\mathrm{SE}}\right)-1\right) \times 1000$ and
} ${ }^{234} \mathrm{U} /{ }^{238} U_{\mathrm{SE}}=(54.891 \pm 0.094) \times 10^{-6}$ (Cheng et al., 2000).
Sub-samples collected in the vicinity of the dated sites were extracted and dated by ICP-QMS; the resulting ages are compared with that expected from the MC-ICPMS age-model.

\subsection{Instrumental}

All measurements were done with an Agilent 7500ce ICP-QMS coupled with an Elemental Scientific APEX-Q high-efficiency sample introduction system, using a PFA microflow nebulizer with a sample uptake of $400 \mu \mathrm{l} / \mathrm{min}$ force-feed by a peristaltic pump. This configuration yields $\sim 10^{6} \mathrm{cps}$ per ppb (ng/g) for ${ }^{238} \mathrm{U}$. Most instrumental variables are summarized in Table 1 . In our system the formation of oxide $\left(\mathrm{UO}^{+} / \mathrm{U}^{+}\right)$and hydride $\left(\mathrm{UH}^{+}\right)$were always below $0.1 \%$ and $0.01 \%$, respectively. Contributions from high intensity peaks onto lower masses were not significant, and always lower than $10 \mathrm{ppm}$ at $\mathrm{m}-1$ (measured at $\mathrm{m} / \mathrm{Z}^{+} 237$ ), and less than $1 \mathrm{ppm}$ at $\mathrm{m}-2$ (measured at $\mathrm{m} / \mathrm{Z}^{+} 236$ ), thus corrections for these potential contributions are negligible. No attempts to measure isotope compositions with the collision cell pressurized were made.

The ICP-QMS is equipped with an ETP electron multiplier which can measure ion beams in pulse-counting (PC), and analogue (A) modes for count-rates lower and higher than $5 \times 10^{6} \mathrm{cps}$, respectively. Because of the differences in the efficiencies between both amplifying sections (Hunter and Stresau, 2005), a detailed crosscalibration procedure between both was developed and is presented below.

Detector dead-time $(\tau)$ was calibrated at 40 ns following the methods recommended by Agilent (2004); an alternative method to calculate $\tau$ (Held and Taylor, 1999) resulted in $\tau=39.7 \pm 1.2 \mathrm{~ns}$. Moreover, ${ }^{234} \mathrm{U} /{ }^{238} \mathrm{U}$ measured at ${ }^{238} \mathrm{U}$ countrates between $2 \times 10^{5}$ and $6 \times 10^{8}$ are essentially identical and do not show any systematic bias, even after correction for efficiencies differences between different amplifying sections of the detector (see below), indicating that $\tau$ is accurate within the attained precision of our measurements.

Because very low-intensity ion-beams ( $<3000 \mathrm{cps}$ ) are expected for the measurement of ${ }^{230} \mathrm{Th}$, it is essential to reduce detector background as much as possible. We achieved this by adjusting the detector discriminator voltage in order to obtain the best signal-tonoise ratio. The voltage is factory-set at $4 \mathrm{mV}$ to produce the highest possible count-rates for routine quantitative analysis; however a 20-40 $( \pm 15)$ cps background was observed under these conditions (Fig. 1). By increasing the discriminator voltage, the U countrate decreases linearly, but the background in the $m / z^{+}$region 228-233 decreases exponentially (Fig. 1), thus the signal-to-noise ratio increases accordingly until it reaches a maximum at $16 \mathrm{mv}$.

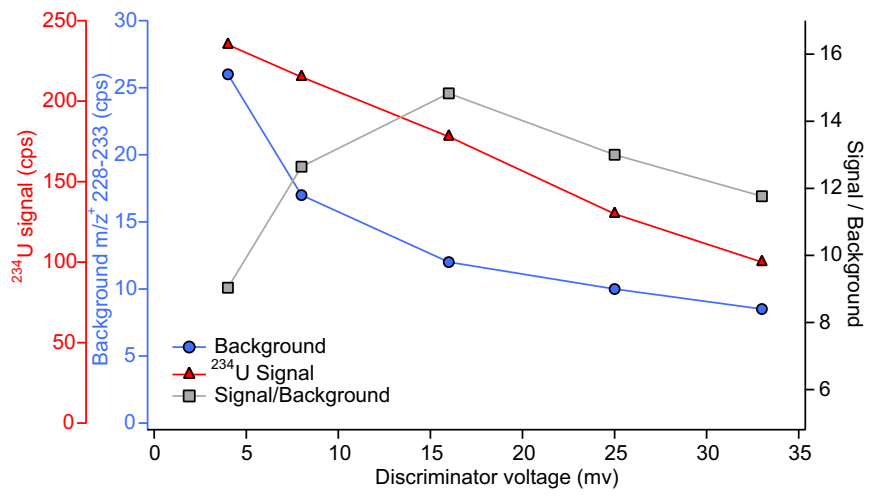

Fig. 1. Effect of the detector discriminator voltage on the ${ }^{234} \mathrm{U}$ signal and background measured as the average signal in the $m / z^{+}$range $228-233$ (left axes) and signal-tonoise ratio (right) from a $5 \mathrm{ng} / \mathrm{g} \mathrm{U}$ solution. 
Under such conditions, a background of $8 \pm 4$ cps was usually obtained, which typically corresponds to a signal-to-noise ratio $>200$ and $>30$ for ${ }^{234} \mathrm{U}$ and ${ }^{230} \mathrm{Th}$, respectively, for a $\sim 20$ ka sample. Further reductions in background were not possible since the detector was reaching the end of its lifetime, and high acceleration voltages applied to the dynodes are required, resulting in such background values.

An additional source of high-background during Th and $U$ analysis is the inefficient removal of residual Th and/or $U$ from the sample introduction system once the sample has been analyzed, leading to potential cross-contamination between samples (Shen et al., 2002; McCulloch and Mortimer, 2008). This is particularly delicate during the analysis of low-intensity ion-beams, such as those from Th, because even a small contamination might increase the ${ }^{230} \mathrm{Th},{ }^{232} \mathrm{Th}$ and ${ }^{229} \mathrm{Th}$ signals leading to incorrect Th-isotope compositions. Consequently the sample introduction system must be thoroughly cleaned after each sample or standard is analyzed until the normal background of $8 \pm 4 \mathrm{cps}$ is reached for all $U$ and Th isotopes. A cleaning routine consisting in four different rinse steps was implemented (McCulloch and Mortimer, 2008), and its effects on the Th and $U$ signals are shown in Fig. 2. The first step consists on rinsing the sample probe tip with de-ionized water; removing any remaining droplet from the previously analyzed sample, and helping to maintain the cleanliness of the forthcoming solutions. Then, a $10 \% \mathrm{HNO}_{3}$ solution, followed by $10 \% \mathrm{HNO}_{3}+1 \%$ Triton (a surfactant) $+0.05 \%$ HF are aspirated; this mixture removes most of the residual Th and $U$. Finally, the last traces of $U$ and Th are removed from the system by aspirating a $2 \% \mathrm{HNO}_{3}$ for few minutes, until normal background levels are reached. Total cleaning time between samples is $\sim 15 \mathrm{~min}$ for $U$, and $\sim 10 \mathrm{~min}$ for Th.

\subsection{Cross calibration between pulse-counting and analogue detection modes}

As mentioned above, the instrument is equipped with an electron multiplier which is divided in two amplifying sections, providing the capability to measure ion-beams up to $10^{9} \mathrm{cps}$. This detection technology is specially attractive for the measurements of very low isotope ratios such as ${ }^{234} \mathrm{U} /{ }^{238} \mathrm{U}$ and ${ }^{230} \mathrm{Th} /{ }^{238} \mathrm{U}$. However, in order to achieve the large dynamic range, it is necessary to correct for the difference in electronic yield between the pulsecount (PC) and analogue (A) modes. This is done in the Agilent 7500ce by calculating a "P/A factor" for each isotope to be analyzed, which cross calibrates the analogue signal to its equivalent in PCmode (Agilent, 2004). P/A factors are calculated by comparing simultaneously the electric response of both amplifying sections to an incident ion beam within a $4 \times 10^{5} \mathrm{cps}$ to $4 \times 10^{6} \mathrm{cps}$ count-rate. In principle, this measurement provides an instrumentally correct figure for the actual difference on the electrical response between both sections of the detector and, thus, provides the spectrometer software with the information required to cross calibrate the signal and extend the linear range. However, initial appraisal on the performance of such correction revealed significant deviations from the expected isotope ratio when the two isotopes are measured in different amplifying sections of the detector (Fig. $3 \mathrm{~A}$ and $C$ ). Note, however, that even in those cases when ${ }^{238} U$ is measured in A-mode, ${ }^{234} \mathrm{U} /{ }^{235} \mathrm{U}$ does not show any bias (Fig. 3B), since both isotopes are always measured in PC-mode.

The differences in detector efficiencies represent a significant source of inaccuracy if uncorrected because, in the absence of a ${ }^{233} \mathrm{U}-{ }^{236} \mathrm{U}$ double spike, we are limited to monitor instrumental mass bias with ${ }^{238} \mathrm{U} /{ }^{235} \mathrm{U}$, and correct assuming a constant composition (137.88) for natural $U$.

To overcome the bias introduced by the differences in detector efficiencies, two options were considered: a) measure ${ }^{229} \mathrm{Th}-{ }^{230} \mathrm{Th}-{ }^{232} \mathrm{Th}$ and ${ }^{233} \mathrm{U}-{ }^{234} \mathrm{U}-{ }^{235} \mathrm{U}-{ }^{238} \mathrm{U}$ in PC-mode, or b) independently measure the detector efficiencies and correct offline. Option A implies that all count-rates should remain below $10^{6}$ cps during the course of the analysis; which can be achieved by analyzing solutions with $<1 \mathrm{ng} / \mathrm{g}$ of ${ }^{238} \mathrm{U}$, with the subsequent loss of precision for the low-abundance isotopes. Alternatively, one could increase the countrate for the low-abundance isotopes by increasing the amount of $U$ introduced, and reference their abundances to ${ }^{235} \mathrm{U}$ instead of ${ }^{238} \mathrm{U}$. This would imply that mass-bias cannot be internally measured and corrected for each sample (since we do not have access to a ${ }^{233} \mathrm{U}-{ }^{236} \mathrm{U}$ double-spike), thus external standardization would be required with a lowconcentration $\mathrm{U}$ standard, so as to be able to measure ${ }^{238} \mathrm{U} /{ }^{235} \mathrm{U}$
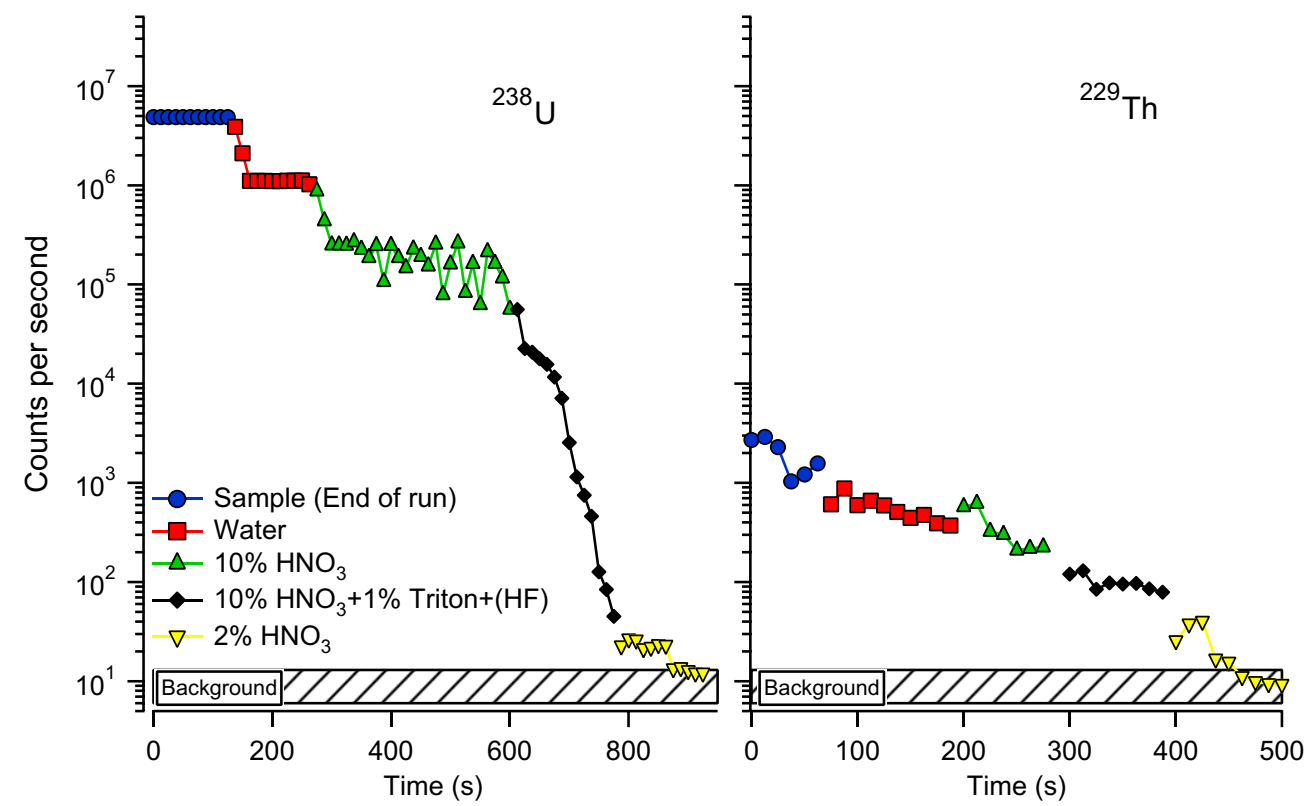

Fig. 2. U and Th washout routine after each sample. The washout profile time are not comparable, but in both cases correspond to actual samples. 


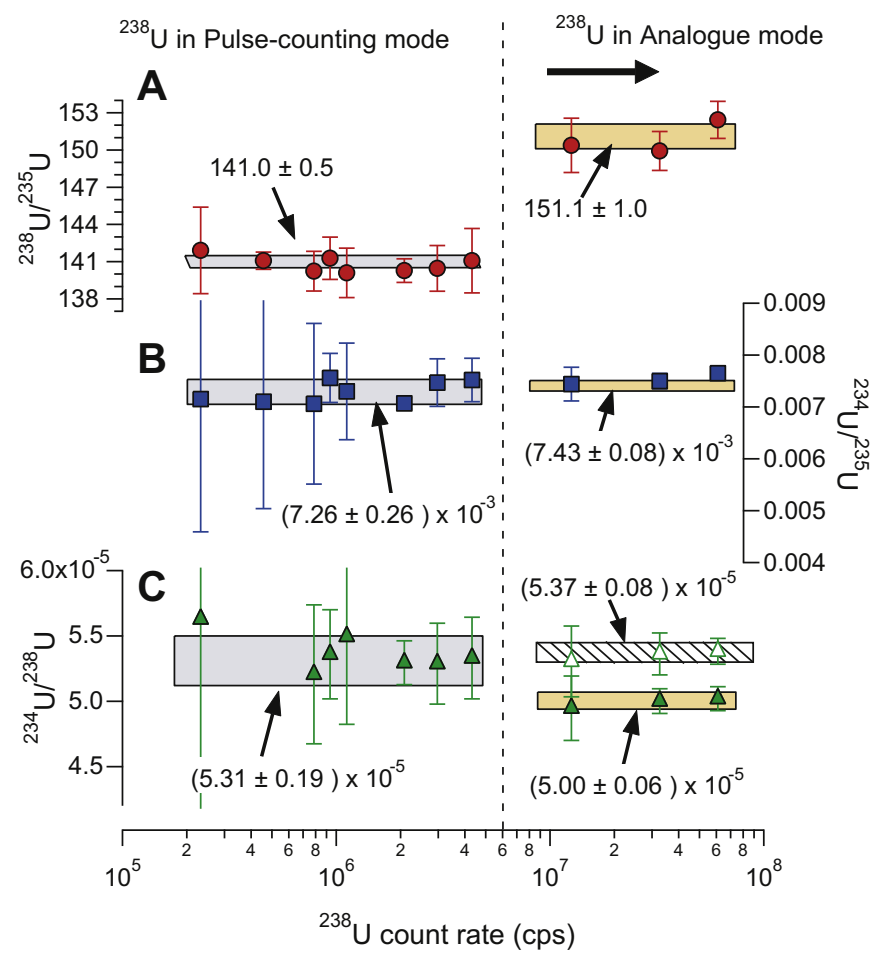

Fig. 3. ${ }^{238} U /{ }^{235} U,{ }^{234} U /{ }^{238} U$, and ${ }^{234} U /{ }^{235} U$ from SRM 960 at different ${ }^{238} U$ countrates. (A) ${ }^{238} \mathrm{U} /{ }^{235} \mathrm{U}$, and $(\mathrm{C}){ }^{234} \mathrm{U} /{ }^{238} \mathrm{U}$ shift when ${ }^{238} \mathrm{U}$ signal reaches analogue mode $\left(>5 \times 10^{6} \mathrm{cps}\right)$; the same sample does not show any shift in ${ }^{234} \mathrm{U} /{ }^{235} \mathrm{U}(\mathrm{B})$ since both isotopes are measured in PC mode. (C) Also shows that ${ }^{234} \mathrm{U} /{ }^{238} \mathrm{U}_{\mathrm{A}}$, after correction by " $F$ " (open symbols), are identical to those measured in PC mode, but the precision is slightly lower due to the quadratic expansion of uncertainties. Shaded squares highlight datapoints used to calculate corresponding average. For some points, uncertainties are smaller that symbol size.

in PC-mode. The latter approach, however, is prone to introduce significant uncertainties as mass-bias might be influenced by the matrix, concentration of the isotopes, and instrumental drift over the course of the analytical session.

In contrast, method B (calibration for differences in detector efficiencies followed by off-line correction), is less prone to uncontrolled bias, and offers the most precise measurement of ${ }^{234} \mathrm{U}$ and ${ }^{230} \mathrm{Th}$ due to their higher countrate. Moreover, whilst the assumption of constant ${ }^{238} \mathrm{U} /{ }^{235} \mathrm{U}$ in nature has been shown to be incorrect (Stirling et al., 2007), the bias introduced by the small deviations in ${ }^{238} \mathrm{U} /{ }^{235} \mathrm{U}$ from the nominal 137.88 are expected to be small $(<0.1 \%$ oo .

In order to cross calibrate between the two amplifying sections, we analyzed a series of solutions of NIST SRM 960 in a range of concentrations between 0.1 and $100 \mathrm{ng} / \mathrm{g}$; this allowed us to measure ${ }^{238} \mathrm{U}$ in both sections of the detector (low- $U$ concentration in PC-mode, and high-U concentration in A-mode), whilst ${ }^{235} \mathrm{U}$ was always measured in PC-mode. We then averaged the ${ }^{238} \mathrm{U} /{ }^{235} \mathrm{U}$ obtained when both isotopes were measured in PC-mode

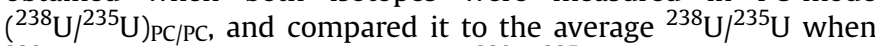

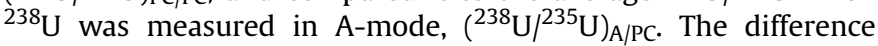
between both is a measure of the bias introduced by the differences in detector efficiency. A correction factor, $\mathrm{F}$, was then calculated as:

$\mathrm{F}=\left(\frac{{ }^{238} \mathrm{U}}{235 \mathrm{U}}\right)_{\mathrm{A} / \mathrm{PC}} /\left(\frac{{ }^{238} \mathrm{U}}{235 \mathrm{U}}\right)_{\mathrm{PC} / \mathrm{PC}}$,

which can then be used to correct all isotope ratios referenced to ${ }^{238} \mathrm{U}$ measured in A-mode. Fig. 3C shows that multiplying ${ }^{234} \mathrm{U} /{ }^{238} \mathrm{U}$ isotope ratios where ${ }^{238} \mathrm{U}$ was measured in A-mode by F, effectively removes any bias introduced by the differences between PC and A modes, as the corrected isotope ratios are statistically identical to those obtained when both isotopes are measured in PC-mode.

In practical terms, the procedure described above for crosscalibration is equivalent to the cross-calibration between electron multipliers and Faraday cups routinely carried out with multicollector spectrometers (TIMS and MC-ICPMS) equipped with one or more SEMs. However, in contrast to the latter, it was not possible for us to obtain the actual count-rates when an ion-beam was measured in both modes during the calculation of P/A factors. Moreover, while F could be measured by simply analyzing only two standards (one for each detection mode), our approach to use three or more solutions for each detection mode decreases significantly the uncertainty associated with $\mathrm{F}$, which is expanded to the corrected ${ }^{234} \mathrm{U} /{ }^{238} \mathrm{U}$. This is particularly important for our methodology because it allows to maintain an acceptable level of precision for ${ }^{234} \mathrm{U} /{ }^{238} \mathrm{U}(<5 \%$ ) after the quadratic expansion of uncertainties. We note that $\mathrm{F}$ does not vary more than $1 \%$ within an analytical session, and less than $1 \%$ between different sessions, as long as the detector acceleration and discriminator voltages are kept constant.

\subsection{Measurement protocol}

When measuring ${ }^{230} \mathrm{Th}-{ }^{234} \mathrm{U}-{ }^{238} \mathrm{U}$, it is important to achieve the highest possible precision, while keeping sample requirements as low as possible. Thus a compromise between sample consumption and precision must be made. Hence, $U$ and Th were measured separately to maximize the counting efficiency and reduce the sample requirements. Counting times were selected giving preference to the low-abundance isotopes $\left({ }^{234} \mathrm{U}\right.$ and $\left.{ }^{230} \mathrm{Th}\right)$ then the tracers $\left({ }^{233} \mathrm{U}\right.$ and $\left.{ }^{229} \mathrm{Th}\right)$ and, finally ${ }^{232} \mathrm{Th},{ }^{235} \mathrm{U}$ and ${ }^{238} \mathrm{U}$ (Table 1). In the case of our ICP-QMS configuration, per-mil level uncertainties for ${ }^{234} \mathrm{U} /{ }^{238} \mathrm{U}$ can be attained from solutions producing an ion-beam of $10^{7} \mathrm{cps}$ for ${ }^{238} \mathrm{U}$ (Fig. 4), equivalent to $\sim 10 \mathrm{ng} / \mathrm{g}$ of ${ }^{238} \mathrm{U}$. However, in order to produce more precise geochronological data with this configuration (low per-mil), while maintaining reasonable sample requirements, we analyzed solutions of $\sim 50 \mathrm{ng} / \mathrm{g}$ of ${ }^{238} \mathrm{U}$, producing $\sim 5 \times 10^{7} \mathrm{cps}$, and resulting in uncertainties of $3-4 \%$ for ${ }^{234} \mathrm{U} /{ }^{238} \mathrm{U}$. This implies that $\sim 500 \mathrm{ng}$ of

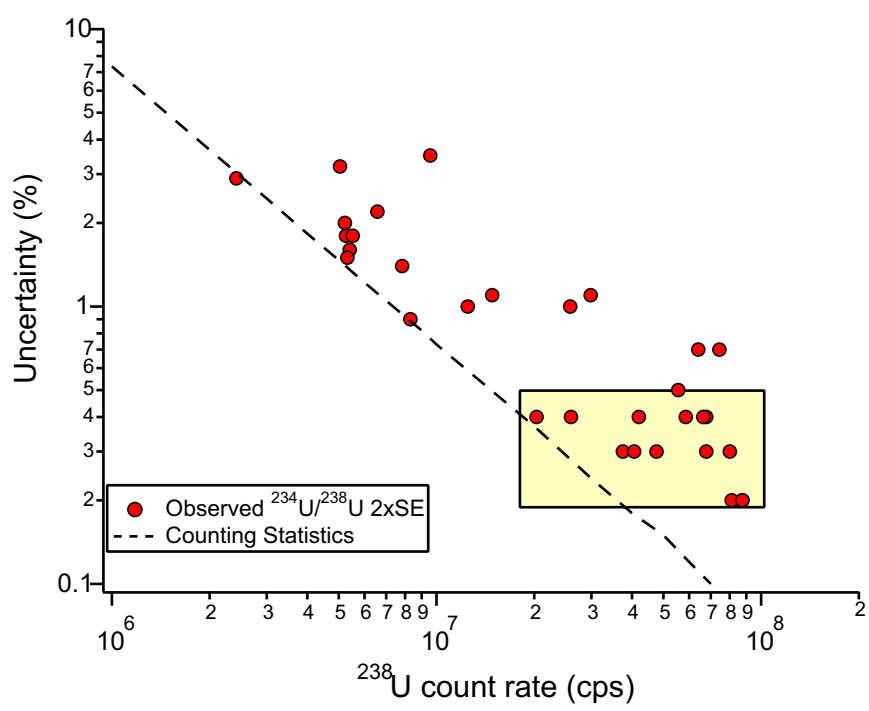

Fig. 4. ${ }^{234} U / /^{238} U$ uncertainty for 47 analysis of un-spiked NIST SRM 960, showing that using our configuration, per-mil precision can only be attained from solutions producing a ${ }^{238} \mathrm{U}$ ion-beam $>10^{7} \mathrm{cps}$. Dashed line indicates the expected uncertainty from counting statistics (taken as $2 \times \sqrt{ } \mathrm{n}$ ). Highlighted square indicates the "working area", where low-permil precision is typically obtained. 
$\mathrm{U}$ are required for each analysis if precision in the low per-mil level is to be achieved. Such levels of uncertainty are approximately $2 \times$ higher than the theoretical precision expected from such countrates (taken as $2 \times \sqrt{ } \mathrm{n}$ ).

\subsection{Data reduction}

Isotope ratios were calculated from background-corrected intensities and, when applicable, corrected for differences in detector efficiencies using Equation (1). The correction factor $\mathrm{F}$ was measured at the beginning of each analytical session and remained essentially constant throughout it (see above). Mass fractionation corrections for ${ }^{233} \mathrm{U} /{ }^{234} \mathrm{U},{ }^{234} \mathrm{U} /{ }^{235} \mathrm{U},{ }^{233} \mathrm{U} /{ }^{238} \mathrm{U},{ }^{229} \mathrm{Th} /{ }^{230} \mathrm{Th}$ and ${ }^{229} \mathrm{Th} /{ }^{232} \mathrm{Th}$ ratios were made following the exponential law (Russell et al., 1978), assuming a constant ${ }^{238} \mathrm{U} /{ }^{235} \mathrm{U}$ value for natural U of $137.88 \pm 0.01$ (Cowan and Adler, 1976) after subtraction of tracer contributions. As discussed above, variability in ${ }^{238} \mathrm{U} /{ }^{235} \mathrm{U}$ (Stirling et al., 2007; Richter et al., 2010) yield ${ }^{234} \mathrm{U} /{ }^{238} \mathrm{U}$ isotope ratios that are not significantly different, and well within the uncertainty of the measurement. Activity ratios were calculated using the generally accepted half-lives for ${ }^{238} \mathrm{U}$ (Jaffey et al., 1971), ${ }^{234} \mathrm{U}$ and ${ }^{230} \mathrm{Th}$ (Cheng et al., 2000) and are denoted by square brackets. All uncertainties reported here correspond to $2 \times$ standard error $(2 \times \mathrm{SE})$ and were expanded quadratically, with the exception of the ${ }^{230}$ Th-age calculation, since Isoplot $2.49 \mathrm{t}$ (Ludwig, 2001) was used for this purpose.

\section{Results and discussion}

\subsection{Analysis of standards}

The accuracy, precision and reproducibility of our methodology was first assessed by analyzing a series of non-spiked aliquots of SRM 960 and $\mathrm{HU}-1$ for ${ }^{234} \mathrm{U} /{ }^{238} \mathrm{U}$, followed by analysis of spiked aliquots for ${ }^{234} \mathrm{U} /{ }^{238} \mathrm{U}$ and ${ }^{230} \mathrm{Th} /{ }^{238} \mathrm{U}$. The results from different analytical sessions are summarized in Fig. 5, where good agreement between measured and expected ${ }^{234} \mathrm{U} /{ }^{238} \mathrm{U}$ compositions is generally observed. The average for our ${ }^{234} \mathrm{U} /{ }^{238} \mathrm{U}$ measurements in NIST SRM 960, $(52.87 \pm 0.072) \times 10^{-6}$, equivalent to $\delta^{234} \mathrm{U}=-36.0 \pm 1.3 \%$ ( $2 \mathrm{SE}, n=18$ ) agrees well with the robust mean calculated from the compilation made by Andersen et al. (2004), $(52.86 \pm 0.021) \times 10^{-6}, \delta^{234} U=-36.87 \pm 0.40 \%$, and also within error of the average of Cheng et al. (2000), $(52.860 \pm 0.025) \times 10^{-6}, \delta^{234} \mathrm{U}=-36.94 \pm 0.45 \%$. For Harwell Uraninite, an average for ${ }^{234} \mathrm{U} /{ }^{238} \mathrm{U}=(54.8 \pm 0.11) \times 10^{-6}$ (2SE, $n=18)$ is also in good agreement with the expected secular equilibrium value of $(54.891 \pm 0.094) \times 10^{-6}$ from Cheng et al. (2000), as well as the robust mean, $(54.875 \pm 0.003) \times 10^{-6}$, calculated from the compilation made by Andersen et al. (2004). In both cases, the average uncertainty of our ${ }^{234} \mathrm{U} /{ }^{238} \mathrm{U}$ measurements is $3-4 \%$, but uncertainties as low as $2 \%$ can be achieved.

Measurements of ${ }^{230} \mathrm{Th} /{ }^{238} \mathrm{U}$ in $\mathrm{HU}-1$ by isotope-dilution are also in good agreement with accepted values. Replicate analysis by isotope-dilution resulted in an average ${ }^{230} \mathrm{Th} /{ }^{238} \mathrm{U}=(16.95 \pm 0.05) \times 10^{-6}(2 \mathrm{SD}, n=4)$, within the uncertainty reported by Cheng et al. (2000). The average uncertainty observed is $\sim 6 \%$, which is about twice the reproducibility of our HU-1 analyses. We note that, under the current analytical conditions, this level of precision is probably the best attainable for ${ }^{230} \mathrm{Th}$ measurements, considering that the precision is mostly limited by its low count-rate, and significantly larger ion beams for ${ }^{230} \mathrm{Th}$ are not expected, since datable samples have ${ }^{230} \mathrm{Th} /{ }^{238} \mathrm{U}$ values that are considerable lower than HU-1. This result implies that, in terms of age calculation, the upper-age limit of our method is $\sim 400 \mathrm{ka}$ (as discussed below).

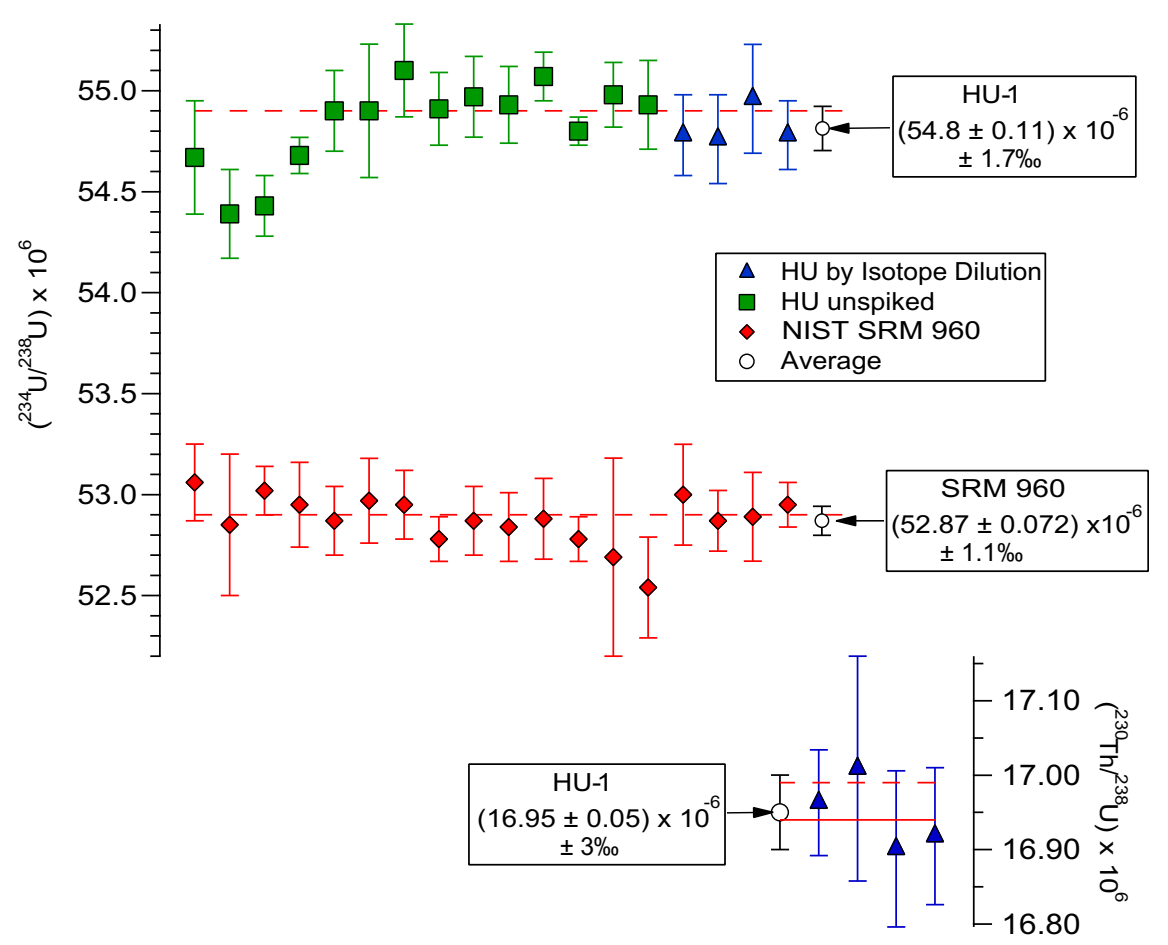

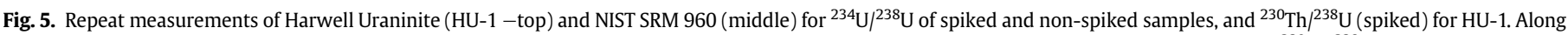

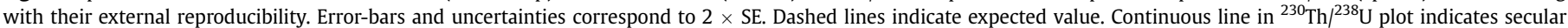

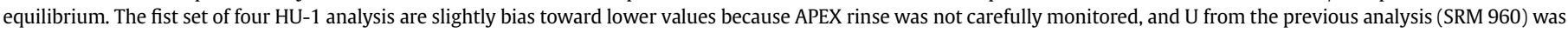
not properly removed from the system. 


\subsection{Analysis of coral fossils}

$\mathrm{U}-\mathrm{Th}$ isotopic data and dates for six coral samples previously dated by MC-ICPMS (Blanchon et al., 2009) are presented in Table 3 and Fig. 6. Good agreement between the MC-ICPMS and ICP-QMS ages is observed. In terms of accuracy, both methods yield undistinguishable data, however, the MC-ICPMS ages are, as expected, significantly more precise than ICP-QMS. The uncertainty of the measured activity ratios for these samples (Table 3 ) is $\sim 3 \%$ and $\sim 15 \%$ for $\left[{ }^{234} \mathrm{U} /{ }^{238} \mathrm{U}\right]$ and $\left[{ }^{230} \mathrm{Th} /{ }^{238} \mathrm{U}\right]$, respectively; which translates into $\sim 3 \%$ uncertainties on a $\sim 125 \mathrm{ka}{ }^{230}$ Th-age.

The ability to measure accurately the initial $\delta^{234} U, \delta^{234} U_{0}$, is essential for the U-series dating of corals, as $\delta^{234} U_{0}$ is commonly used a tracer for diagenetic alteration (Edwards et al., 2003). Deviations larger than $\pm 15 \%$ from the modern-day $\delta^{234} U$ in seawater (146.8 $\pm 0.1 \%$, Andersen et al., 2010) in coral fossils as old as $370 \mathrm{ka}$, strongly suggest that the isotopic composition of the sample has been altered, thus the ${ }^{230} \mathrm{Th}$-age is not reliable (Gallup et al., 1994; Stirling et al., 1995, 1998, 2001; Henderson, 2002). Due to the lack of geological reference materials certified for their $\delta^{234} \mathrm{U}$ composition, these samples are particularly relevant to assess the accuracy of our $\delta^{234} \mathrm{U}$ measurements in real samples, since our ${ }^{233} \mathrm{U}$ tracer contains traces of ${ }^{234} \mathrm{U}$ (Table 2), which has to be taken into account during data reduction.

Fig. 6 shows the $\delta^{234} U_{0}$ values for the six corals analyzed by isotope-dilution. Good agreement between the MC-ICPMS and ICPQMS results is obtained; as expected, the latter yields lower precision ( $3 \%$ vs. $4.5 \%$ ). The accuracy and precision of our method appears to be sufficient to correctly discriminate between those samples that have suffered diagenetic alteration from those that have pristine isotopic composition. Small differences between the $\delta^{234} \mathrm{U}_{0}$ from MC-ICPMS and ICP-QMS are discernable for some aliquots of samples XA4-2 and XE2-2, $\left(\Delta \delta^{234} U-5 \%\right.$ ), however, these do not lead to different conclusions regarding the reliability of the corresponding ${ }^{230}$ Th-ages.

\subsection{Analysis of stalagmites}

Fig. 7 shows the age models for the two different stalagmites previously dated by MC-ICPMS at the ANU. Three MC-ICPMS ages constrain the growth of stalagmite COYO-04 between $72.30 \pm 0.86$ and $55.84 \pm 1.24 \mathrm{ka}$ at a rate of $5.3 \pm 0.27 \mathrm{~mm} / \mathrm{ka}$ (from a linear

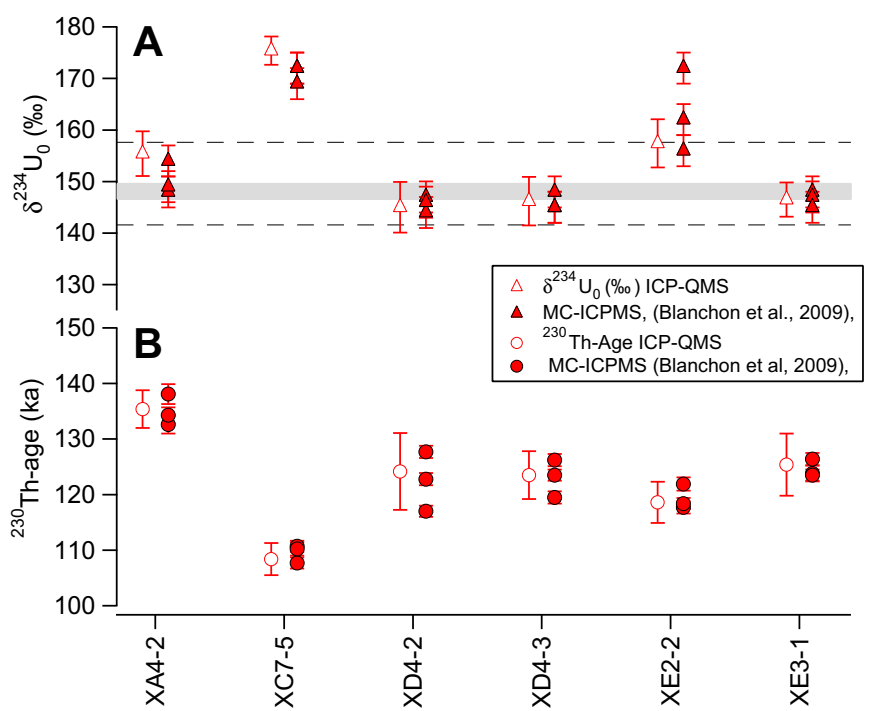

Fig. 6. Comparison of $\delta^{234} U$ (top) and ${ }^{230} \mathrm{Th}$-age (bottom) for six last-interglacia samples of A. Palmata previously dated by MC-ICPMS (Blanchon et al., 2009) with ICP-QMS data from. Open symbols correspond to ICP-QMS, filled symbols different replicates obtained by MC-ICPMS. In both cases error bars correspond to $2 \times \mathrm{SE}$. Shaded area correspond to isotopic compositions indicating "strictly reliable" data $\left(\delta^{234} U_{0}=146.6-149.6 \%\right.$, while dashed lines limit the "reliable" isotope composition; both criteria established in Blanchon et al. (2009).

error-weighted regression, Fig. 7A). For this study, four samples from stalagmite COYO-04, including replicates, were analyzed. All the ICP-QMS dated samples from this stalagmite fall within the age model previously established, and allow to refine it. A slightly slower growth rate $(5.2 \pm 0.3 \mathrm{~mm} / \mathrm{ka})$ is obtained once the ICP-QMS dated samples are incorporated into the age-model. By linearly extrapolating the MC-ICPMS age-model, we estimate the age for the tip at $50.1 \mathrm{ka}$, which is slightly biased from the ${ }^{230}$ Th-age of $51.1 \pm 0.8$ ka obtained by ICP-QMS. However, a refined age-model based upon the MC-ICPMS and ICP-QMS ages, produces a seconddegree equation which estimates the age of the tip at $51.12 \mathrm{ka}$, in excellent agreement with the ${ }^{230} \mathrm{Th}$-age obtained here.

The age-model for stalagmite COYO-01 is based on five MCICPMS samples. The stalagmite grew between $\sim 25.5$ and $22.5 \mathrm{ka}$; however, in contrast to COYO-04, the growth-history of COYO-01 is

Table 3

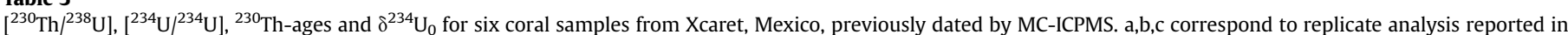

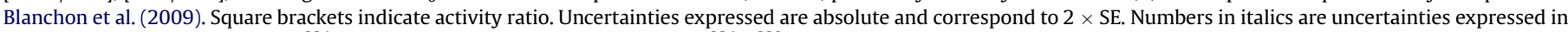

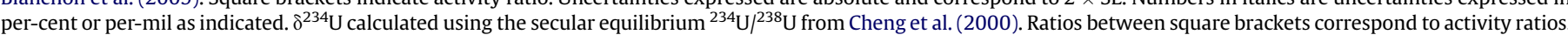

\begin{tabular}{|c|c|c|c|c|c|c|c|c|c|c|c|c|c|}
\hline Sample & {$\left[{ }^{230} \mathrm{Th} /{ }^{238} \mathrm{U}\right]$} & $\begin{array}{l} \pm \\
(\%)\end{array}$ & {$\left[{ }^{234} \mathrm{U} /{ }^{238} \mathrm{U}\right]$} & $\begin{array}{c} \pm \\
(\%)\end{array}$ & $\begin{array}{c}{ }^{230} \text { Th-ages } \\
\text { (ka) }\end{array}$ & $\begin{array}{c} \pm \\
(\%)\end{array}$ & $\begin{array}{c}\delta^{234} \mathrm{U}_{0} \\
(\%)\end{array}$ & \pm & & $\begin{array}{l}{ }^{230} \text { Th-age } \\
\text { (expected) }\end{array}$ & \pm & $\begin{array}{l}\delta^{234} \mathrm{U}_{0} \\
\text { (expected) }\end{array}$ & \pm \\
\hline \multirow[t]{3}{*}{ XA4-2 } & & 0.0118 & & 0.0034 & & 4.3 & & & $a$ & 138.1 & 1.8 & 154 & 3 \\
\hline & 0.803 & $(1.5)$ & 1.1084 & (3.1) & 135 & $(3.2)$ & 155 & 3 & b & 132.6 & 1.6 & 148 & 3 \\
\hline & & & & & & & & & c & 134.3 & 1.4 & 149 & 3 \\
\hline \multirow[t]{3}{*}{ XC7-5 } & & 0.0097 & & 0.0029 & & 2.7 & & & $\mathrm{a}$ & 110.7 & 1 & 172 & 3 \\
\hline & 0.726 & (1.33) & 1.1318 & $(2.5)$ & 108 & $(2.5)$ & 175 & 3 & b & 107.7 & 1 & 172 & 3 \\
\hline & & & & & & & & & c & 110.2 & 1.2 & 169 & 3 \\
\hline \multirow[t]{3}{*}{ XD4-2 } & & 0.015 & & 0.0069 & & 4.9 & & & $\mathrm{a}$ & 117 & 1 & 147 & 3 \\
\hline & 0.763 & $(1.9)$ & 1.1046 & $(6.3)$ & 124 & $(3.9)$ & 145 & 7 & b & 122.8 & 1.1 & 144 & 3 \\
\hline & & & & & & & & & c & 137.7 & 1.1 & 146 & 3 \\
\hline \multirow[t]{3}{*}{ XD4-3 } & & 0.015 & & 0.0043 & & 4.7 & & & $\mathrm{a}$ & 119.5 & 1.1 & 148 & 3 \\
\hline & 0.762 & (1.9) & 1.1056 & (3.9) & 123 & $(3.8)$ & 146 & 4 & b & 126.2 & 1.1 & 145 & 3 \\
\hline & & & & & & & & & c & 123.5 & 1 & 145 & 3 \\
\hline \multirow[t]{3}{*}{ XE2-2 } & & 0.016 & & 0.0037 & & 4.7 & & & $\mathrm{a}$ & 117.7 & 1.1 & 156 & 3 \\
\hline & 0.752 & $(2.1)$ & 1.1151 & $(3.3)$ & 118 & $(4.0)$ & 157 & 4 & b & 121.9 & 1.2 & 162 & 3 \\
\hline & & & & & & & & & c & 118.4 & 1 & 172 & 3 \\
\hline \multirow[t]{3}{*}{ XE3-1 } & & 0.0086 & & 0.0056 & & 3.3 & & & $\mathrm{a}$ & 123.8 & 1.4 & 148 & 3 \\
\hline & 0.768 & $(1.13)$ & 1.1053 & $(5.1)$ & 128 & $(2.6)$ & 146 & 5 & b & 123.5 & 1 & 147 & 3 \\
\hline & & & & & & & & & c & 126.4 & 1.1 & 145 & 3 \\
\hline
\end{tabular}




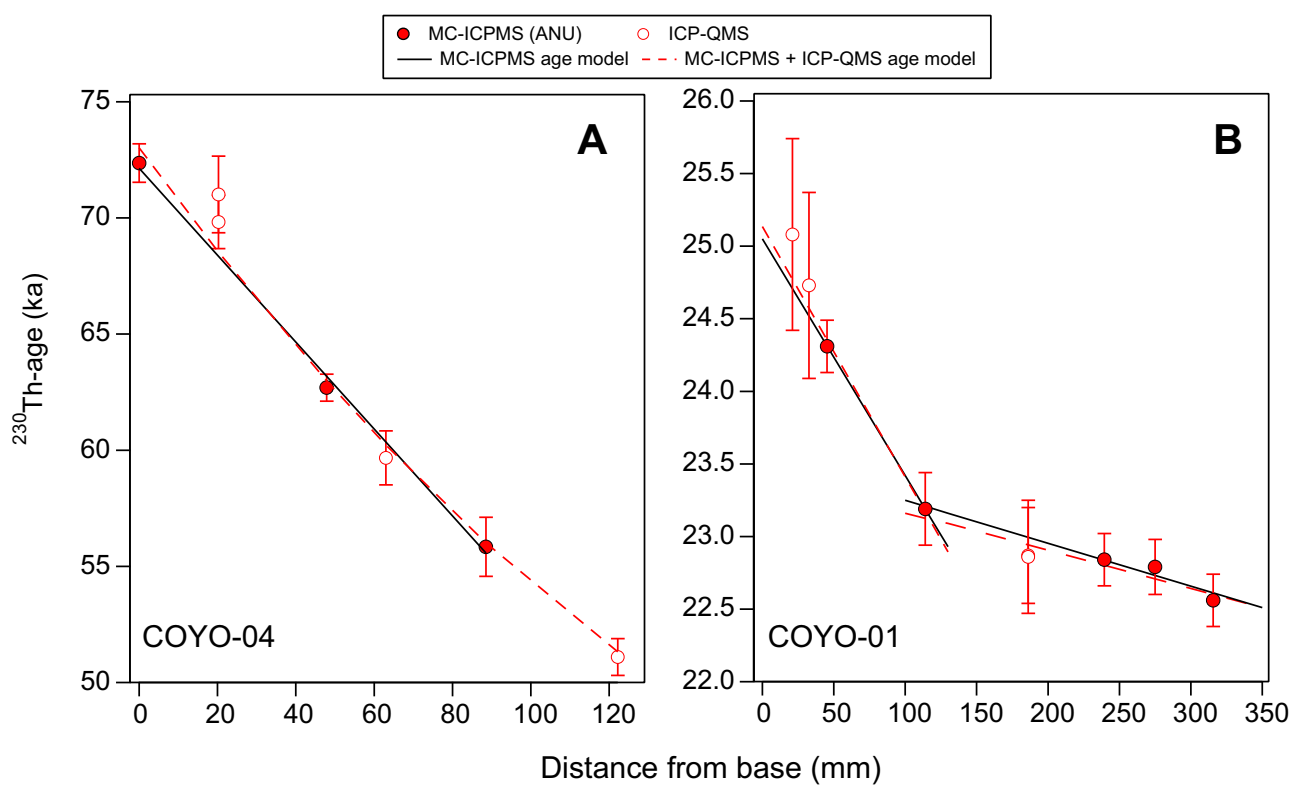

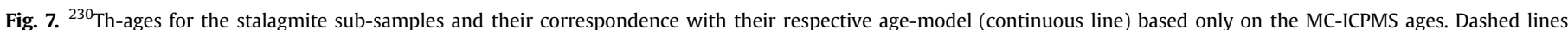

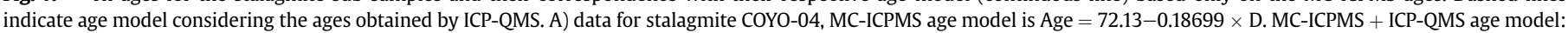

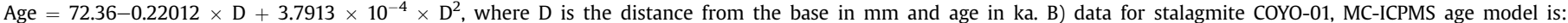

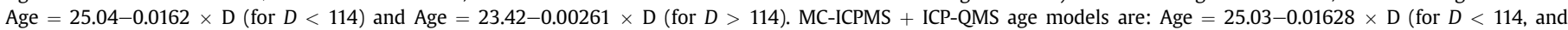
Age $=23.53-0.0029 \times \mathrm{D}$ (For $D>114)$, where $\mathrm{D}$ is the distance form the base in $\mathrm{mm}$, and age in ka.

slightly more complex (Fig. 7B): a growth rate of $\sim 60 \mathrm{~mm} / \mathrm{ka}$ is estimated between 24.1 and $23.1 \mathrm{ka}$, and abruptly increases to $340 \pm 37 \mathrm{~mm} / \mathrm{ka}$ between 23.1 and $22.5 \mathrm{ka}$. Four samples dated by ICP-QMS agree well with this model and allow to refine it; two samples with expected ages of 24.5 and $24.7 \mathrm{ka}$, yield ${ }^{230} \mathrm{Th}$-ages of $24.73 \pm 0.64$ and $25.08 \pm 0.66 \mathrm{ka}$, respectively; an error-weighted age-model indicates that the growth rate for this stalagmite is $58 \pm 12 \mathrm{~mm} / \mathrm{ka}$, in excellent agreement with the estimation made from the MC-ICPMS ages. Two additional samples ran as replicates produced identical ${ }^{230} \mathrm{Th}$-ages $(22.87 \pm 0.33$ and $22.86 \pm 0.39 \mathrm{ka})$, which are also in perfect agreement with their stratigraphic position, and provide additional robustness to the corresponding section of the age-model (Fig. 7).

\subsection{Analytical constrains and their geochronological implications}

We have demonstrated that ICP-QMS coupled with a highefficiency sample introduction system, provides the required sensitivity to accurately measure ${ }^{234} U$ and ${ }^{230} \mathrm{Th}$, resulting in $\delta^{234} \mathrm{U}$ values and ${ }^{230} \mathrm{Th}$-ages which are consistent with independent measurements from two different laboratories and methodologies. However, the sequential nature of the measurement, along with the inherent characteristics of quadrupoles producing Gaussian-peaks for each isotope result in ${ }^{230} \mathrm{Th}$-ages with $\sim 5 \%$ uncertainties. This, combined with the isotopic composition of our ${ }^{229} \mathrm{Th}$ tracer, represents a limitation for analyzing samples with ages near or at the upper and lower dating-limits by U-series geochronology.

A good analogue for the analysis of very old samples is HU-1 which, in practical terms, is in secular equilibrium with respect to ${ }^{234} \mathrm{U} /{ }^{238} \mathrm{U}$ and ${ }^{230} \mathrm{Th} /{ }^{238} \mathrm{U}$. Our isotope-dilution results for $\mathrm{HU}-1$ have average uncertainties of $\pm 4 \%$ and $\pm 6 \%$ for ${ }^{234} \mathrm{U} /{ }^{238} \mathrm{U}$ and ${ }^{230} \mathrm{Th} /{ }^{238} \mathrm{U}$, respectively. This implies that samples with $\mathrm{U}$ activity ratios $\left[{ }^{234} \mathrm{U} /{ }^{238} \mathrm{U}\right]<1.004$ (assuming most specimens have ${ }^{234} \mathrm{U} /{ }^{238} \mathrm{U}$ higher than secular equilibrium) and $\left[{ }^{230} \mathrm{Th} /{ }^{238} \mathrm{U}\right]>0.994$, cannot be dated with our methodology and instrumentation. Consequently, an age upper-limit of $407 \pm 36$ ka can be assumed, which is also ultimately dependant on the $\left[{ }^{234} \mathrm{U} /{ }^{238} \mathrm{U}\right]_{\text {initial }}$ of the sample.

Dating of very young samples is limited not only by the precision of the measurement, but also by the composition of the ${ }^{229} \mathrm{Th}$ tracer, and the detector background. Considering the latter at $8 \pm 4 \mathrm{cps}$, and ${ }^{229} \mathrm{Th} /{ }^{230} \mathrm{Th}=650 \pm 21$ for our ${ }^{229} \mathrm{Th}$ tracer (Table 2), along with a ${ }^{229} \mathrm{Th}$ countrate of $\sim 5000 \mathrm{cps}$, we estimate that the lowest $\left[{ }^{230} \mathrm{Th} /{ }^{238} \mathrm{U}\right]$ activity ratio measureable with our methodology and instrumentation is $\sim 0.017 \pm 0.004$, which corresponds to $\mathrm{a}^{230} \mathrm{Th}$-age of $0.83 \pm 0.48 \mathrm{ka}$ for a $\left[{ }^{234} \mathrm{U} /{ }^{238} \mathrm{U}\right]=1.000 \pm 0.004$. This dating limit, and its absolute uncertainty, decreases exponentially for $\left[{ }^{234} U /{ }^{238} U\right]>1.000$; however, in practical terms, samples younger than 1000 years cannot be dated reliably by our methodology and instrumentation.

The assumption that natural $U$ has a constant ${ }^{238} U /{ }^{235} U$ has been recently demonstrated to be incorrect (Stirling et al., 2007; Weyer et al., 2008; Bopp et al., 2009; Brennecka et al., 2010). A shift as large as $1 \%$ in ${ }^{238} \mathrm{U} /{ }^{235} \mathrm{U}$ has been observed in stalagmite calcite (Stirling et al., 2007), which can result in 30-100-year shifts in the calculated ${ }^{230} \mathrm{Th}$-age, for $30 \mathrm{ka}$ and 100 ka old samples, respectively. Such age-displacements are well within the uncertainty of our measurements and calculated ages. However, larger ${ }^{238} \mathrm{U} /{ }^{235} \mathrm{U}$ fractionations cannot be ruled out in low-temperature environments where adsorption appears to be a significant fractionation factor, which would impinge a more noticeable bias in calculated ${ }^{230} \mathrm{Th}$-ages, if un-accounted. The use of gravimetric ${ }^{233} \mathrm{U}-{ }^{236} \mathrm{U}$ double spikes eliminates the potential of such bias.

\section{Conclusions}

We are able to accurately measure large isotope ratios, such as ${ }^{234} \mathrm{U} /{ }^{238} \mathrm{U}$ and ${ }^{230} \mathrm{Th} /{ }^{238} \mathrm{U}$ with reasonable good precision and sample requirement using an ICP-QMS. This required a careful characterization of the detector performance for measuring low and high count-rates, and minimizing any bias introduced by the differences in detector efficiency between the different amplifying sections. This has allowed us to demonstrate the feasibility of using 
ICP-QMS coupled with a high efficiency sample introduction system to produce accurate ${ }^{230} \mathrm{Th}$-ages and $\delta^{234} \mathrm{U}$ values, comparable to those obtained by MC-ICPMS over a wide range of ages, from secular equilibrium to $\sim 20 \mathrm{ka}$, but with slightly lower precision than multicollector methodologies.

The precision attained is, however, sufficient to produce isotopic and geochronological meaningful data, and provides a low-cost option for laboratories lacking access to high-precision instrumentation. Moreover, our methodology can also be used to obtain reconaissance geochronological information in order to build preliminary age-models and time-series, thus the user is able to select samples for detailed high-precision dating using multicollector ICPMS instrumentation as required.

Improvements in precision can be achieved by the use of a ${ }^{233} \mathrm{U}-{ }^{236} \mathrm{U}$ double spike, to monitor and correct for instrumental mass-bias. Furthermore, the use of such a double spike will eliminate any potential bias introduced by the fractionation in ${ }^{238} \mathrm{U} /{ }^{235} \mathrm{U}$, and enhance even more the accuracy of the methodology. Additionally, the use of a ${ }^{229} \mathrm{Th}$ spike of higher purity that the one used in this paper, is essential to improve the dating of very young samples. Moreover, further improvements in detection technology, ion production, extraction and transmission in for ICP-QMS will also reflect in lower sample requirements and improved precision.

\section{Acknowledgments}

Comments by Claudine Stirling and an anonymous reviewer significantly enhanced the clarity of this paper and it is greatly appreciated. Discussions between JPB, Michael Shelley and Kenichi Sakata during the very early stages of this work on the effect of " $\mathrm{P} / \mathrm{A}$ factors" and the detector performance upon the accuracy of isotope ratio measurement proved essential to develop the detector crosscalibration procedure discussed in the paper. Funding for this work was provided by Consejo Nacional de Ciencia y Tecnología grants 44016 and 78828 and PAPIT/UNAM grant 112008 to JPB. CTICUNAM provided vital funding for acquiring the ICP-QMS used in this work, as well as for travel expenses for JPB to the ANU. EHM thanks CONACyT for a postgraduate MS scholarship. Funding from the ARC Centre of Excellence in Coral Reef Studies to MTM supported this study. The authors wish to thank Paul Blanchon (ICMyLUNAM) for providing the coral samples analyzed in this work.

Editorial handling by: D.A. Richards

\section{References}

Agilent, 2004. Agilent 7500 ICP-MS Hardware Manual.

Andersen, M.B., Stirling, C.H., Potter, E.-K., Halliday, A.N., 2004. Toward epsilon levels of measurement precision on ${ }^{234} \mathrm{U} /{ }^{238} \mathrm{U}$ by using MC-ICPMS. International Journal of Mass Spectrometry 237 (2-3), 107-118.

Andersen, M.B., Stirling, C.H., Potter, E.-K., Halliday, A.N., Blake, S.G., McCulloch, M.T., Ayling, B.F., O'Leary, M., 2008. High-precision U-series measurements of more than 500,000 year old fossil corals. Earth and Planetary Science Letters 265 (1-2), 229-245.

Andersen, M.B., Stirling, C.H., Zimmermann, B., Halliday, A.N., 2010. Precise determination of the open ocean ${ }^{234} \mathrm{U} /{ }^{238} \mathrm{U}$ composition. Geochemistry Geophysics Geosystems 11 (12), Q12003.

Bandura, D.R., Baranov, V.I., Tanner, S.D., 2000. Effect of collisional damping and reactions in a dynamic reaction cell on the precision of isotope ratio measurements. Journal of Analytical Atomic Spectrometry 15 (8), 921-928.

Bernal, J.P., Eggins, S.M., McCulloch, M.T., 2005. Accurate in situ ${ }^{238} \mathrm{U}-{ }^{234} \mathrm{U}-{ }^{232} \mathrm{Th}-{ }^{230} \mathrm{Th}$ analysis of silicate glasses and iron oxide by laser-ablation MC-ICP-MS. Journal of Analytical Atomic Spectrometry 20 (11), 1240-1249.

Black, L.P., Kamo, S.L., Allen, C.M., Davis, D.W., Aleinikoff, J.N., Valley, J.W., Mundil, R., Campbell, I.H., Korsch, R.J., Williams, I.S., Foudoulis, C., 2004. Improved ${ }^{206} \mathrm{~Pb} /{ }^{238} \mathrm{U}$ microprobe geochronology by the monitoring of a trace-elementrelated matrix effect; SHRIMP, ID-TIMS, ELA-ICP-MS and oxygen isotope documentation for a series of zircon standards. Chemical Geology 205 (1-2), 115-140.

Blanchon, P., Eisenhauer, A., Fietzke, J., Liebetrau, V., 2009. Rapid sea-level rise and reef back-stepping at the close of the last interglacial highstand. Nature 458 (7240), 881-884.
Bopp, C.J., Lundstrom, C.C., Johnson, T.M., Glessner, J.J.G., 2009. Variations in proposits:

Bourdon, B., Henderson, G.M., Lundstrom, C.C., Turner, C., 2003. Uranium-series geochemistry: reviews in mineralogy. Geochemical Society \& Mineralogical Society of America 52, 656.

Bradshaw, N., J, H.E.F., Sanderson, N.E., 1989. Inductively coupled plasma as an ion source for high-resolution mass spectrometry. Journal of Analytical Atomic Spectrometry 4, 801 .

Brennecka, G.A., Borg, L.E., Hutcheon, I.D., Sharp, M.A., Anbar, A.D., 2010. Natural variations in uranium isotope ratios of uranium ore concentrates: understanding the ${ }^{238} \mathrm{U} /{ }^{235} \mathrm{U}$ fractionation mechanism. Earth and Planetary Science Letters 291 (1-4), 228-233.

Cali, J.P., 1972. National Bureau of Standards Certificate of Analysis Standard Reference Material 960-Uranium Metal. National Bureau of Standards, Washington D.C.

Condon, D.J., McLean, N., Noble, S.R., Bowring, S.A., 2010. Isotopic composition $\left({ }^{238} \mathrm{U} /{ }^{235} \mathrm{U}\right)$ of some commonly used uranium reference materials. Geochimica et Cosmochimica Acta 74 (24), 7127-7143.

Cowan, G.A., Adler, H.H., 1976. The variability of the natural abundance of ${ }^{235} \mathrm{U}$ Geochimica et Cosmochimica acta 40, 1487-1490.

Chen, J.H., Lawrence Edwards, R., Wasserburg, G.J., $1986 .{ }^{238} \mathrm{U},{ }^{234} \mathrm{U}$ and ${ }^{232} \mathrm{Th}$ in seawater. Earth and Planetary Science Letters 80 (3-4), 241-251.

Cheng, H., Edwards, R.L., Hoff, J., Gallup, C.D., Richards, D.A., Asmerom, Y., 2000. The half-lives of uranium-234 and thorium-230. Chemical Geology 169 (1-2), 17-33.

De Muynck, D., Cloquet, C., Vanhaecke, F., 2008. Development of a new method for $\mathrm{Pb}$ isotopic analysis of archaeological artefacts using single-collector ICPdynamic reaction cell-MS. Journal of Analytical Atomic Spectrometry 23 (1) 62-71. doi:10.1039/b709461b.

Douville, E., Sallé, E., Frank, N., Eisele, M., Pons-Branchu, E., Ayrault, S., 2010. Rapid and accurate U-Th dating of ancient carbonates using inductively coupled plasma-quadrupole mass spectrometry. Chemical Geology 272 (1-4), 1-11.

Edwards, R.L., Chen, J.H., Wasserburg, G.J., 1987. ${ }^{238} \mathrm{U},{ }^{234} \mathrm{U},{ }^{230} \mathrm{Th}-{ }^{232} \mathrm{Th}$ systematics and the precise measurement of time over the past 500000 years. Earth \& Planetary Science Letters 81, 175-192.

Edwards, R.L., Gallup, C.D., Cheng, H., 2003. Uranium-series dating of marine and lacustrine carbonates. In: Bourdon, B., Henderson, G.M., Lundstrom, C.C., Turner, S.P. (Eds.), Uranium-series Geochemistry. Reviews in Mineralogy and Geochemistry. Geochemical Society and Mineralogical Society of America, pp. 363-405.

Fietzke, J., Liebetrau, V., Eisenhauer, A., Dullo, C., 2005. Determination of uranium isotope ratios by multi-static MIC-ICP-MS: method and implementation for precise U- and Th-series isotope measurements. Journal of Analytical Atomic Spectrometry 20 (5), 395-401.

Gallup, C.D., Edwards, R.L., Johnson, R.G., 1994. The timing of high sea levels over the past 200,000 years. Science 263 (5148), 796-800.

Goldstein, S.J., Stirling, C.H., 2003. Techniques for measuring Uranium-series nuclides: 1992-2002. In: Bourdon, B., Henderson, G.M., Lundstrom, C.C. Turner, S.P. (Eds.), Uranium-Series Geochemistry. Reviews in Mineralogy and Geochemistry. Geochemical Society and Mineralogical Society of America.

Held, A., Taylor, P.D.P., 1999. A calculation method based on isotope ratios for the determination of dead time and its uncertainty in ICP-MS and application of the method to investigating some features of a continuous dynode multiplier. Journal of Analytical Atomic Spectrometry 14 (7), 1075-1079.

Hellstrom, J.C., 2003. Rapid and accurate U/Th dating using parallel ion-counting multi-collector ICP-MS. Journal of Analytical Atomic Spectrometry 18 1346-1351.

Henderson, G.M., 2002. Seawater $\left({ }^{234} U /{ }^{238} U\right)$ during the last 800 thousand years. Earth \& Planetary Science Letters 199 (1-2), 97-110.

Hernández-Mendiola, E., Bernal, J.P., Lounojeva, E., McCulloch, M.T., Morales, P., Cienfuegos, E., 2007. Comparison of new geochemical proxies in a stalagmite from sub tropical Mexico. Eos Electronic Supplement - AGU 88 (23), Jt. Assem. Suppl., Abstract PP43C-09.

Hoffmann, D.L., 2008. ${ }^{230} \mathrm{Th}$ isotope measurements of femtogram quantities for Useries dating using multi ion counting (MIC) MC-ICPMS. International Journal of Mass Spectrometry 275 (1-3), 75-79.

Hoffmann, D.L., Prytulak, J., Richards, D.A., Elliott, T., Coath, C.D., Smart, P.L., Scholz, D., 2007. Procedures for accurate $U$ and Th isotope measurements by high precision MC-ICPMS. International Journal of Mass Spectrometry 264 (23), 97-109.

Horn, I., Rudnick, R.L., McDonough, W.F., 2000. Precise elemental and isotope ratio determination by simultaneous solution nebulization and laser ablation-ICPMS: application to U-Pb geochronology. Chemical Geology 167, 405-425.

Houk, R.S., Fassel, V.A., Flesch, G.D., Svec, H.J., Gray, A.L., Taylor, C.E., 1980. Inductively coupled argon plasma as an ion source for mass spectrometric determination of trace elements. Analytical Chemistry 52, 2283-2289.

Howritz, E.P., Chiarizia, R., Dietz, M.L., Diamond, H., 1993. Separation and preconcentration of actinides from acidic media by extraction chromatography. Analytica Chimica Acta 281, 361-372.

Hunter, K., 1994. Ion detection in icp-mass spectrometry using active film multipliers. Atomic Spectroscopy 15 (1), 17-20.

Hunter, K., Stresau, D., 2005. Ion detection. In: Nelms, S.M. (Ed.), Inductively Coupled Plasma Mass Spectrometry Handbook. Blackwell Publishing Ltd., Oxford, pp. 117-143. 
Jaffey, A.H., Flynn, K.F., Glendenin, L.E., Bentley, W.C., Essling, A.M., 1971. Precision measurement of half-lives and specific activities of ${ }^{235} \mathrm{U}$ and ${ }^{238} \mathrm{U}$. Physical Review C 4 (5), 1889-1906.

Kosler, J., Fonneland, H., Sylvester, P., Tubrett, M., Pedersen, R.-B., 2002. U-Pb dating of detrital zircons for sediment provenance studies-a comparison of lase ablation ICPMS and SIMS techniques. Chemical Geology 182 (2-4), 605-618.

Ludwig, K.R., 2001. Users Manual for Isoplot/Ex. Rev. 2.49. Special publication No. 1a. Berkeley Geochronology Center, Berkeley, CA.

Luo, X., Rehkamper, M., Lee, D.-C., Halliday, A.N., 1997. High precision ${ }^{230} \mathrm{Th} /{ }^{232} \mathrm{Th}$ and ${ }^{234} \mathrm{U} /{ }^{238} \mathrm{U}$ measurements using energy-filtered ICP magnetic sector multiple collector mass spectrometry. International Journal of Mass Spectrometry and Ion Processes 171 (1-3), 105-117.

Mas, J., Ma, R., McLeod, C., González-Labajo, J., Cox, A., Watson, P., 2006. Determination of ${ }^{234} \mathrm{U} /{ }^{238} \mathrm{U}$ isotope ratios in environmental waters by quadrupole ICPMS after U stripping from alpha-spectrometry counting sources. Analytical and Bioanalytical Chemistry 386 (1), 152-160.

McCulloch, M.T., Mortimer, G.E., 2008. Applications of the U-238-Th-230 decay series to dating of fossil and modern corals using MC-ICPMS. Australian Journal of Earth Sciences 55 (6-7), 955-965.

McGregor, H.V., Hellstrom, J., Fink, D., Hua, Q., Woodroffe, C.D. 2011. Rapid U-series dating of young fossil corals by laser ablation MC-ICPMS. Quaternary Geochronology 6 (2), 195-206.

Pietruszka, A.J., Carlson, R.W., Hauri, E.H., 2002. Precise and accurate measurement of ${ }^{226} \mathrm{Ra}-{ }^{230} \mathrm{Th}-{ }^{238} \mathrm{U}$ disequilibria in volcanic rocks using plasma ionization multicollector mass spectrometry. Chemical Geology 188 (3-4), 171-191.

Potter, E.-K., Stirling, C.H., Andersen, M.B., Halliday, A.N., 2005a. High precision Faraday collector MC-ICPMS thorium isotope ratio determination. International Journal of Mass Spectrometry 247 (1-3), 10-17.

Potter, E.-K., Stirling, C.H., Wiechert, U.H., Halliday, A.N., Spotl, C., 2005b. Uraniumseries dating of corals in situ using laser-ablation MC-ICPMS. International Journal of Mass Spectrometry 240 (1), 27-35.

Richter, S., Eykens, R., Kühn, H., Aregbe, Y., Verbruggen, A., Weyer, S., 2010. New average values for the $n\left({ }^{238} U\right) / n\left({ }^{235} U\right)$ isotope ratios of natural uranium standards. International Journal of Mass Spectrometry 295 (1-2), 94-97.

Russell, W.A., Papanastassiou, D.A., Tombrello, T.A., 1978. Ca isotope fractionation on the Earth and other solar system materials. Geochimica et Cosmochimica Acta 42, 1075-1090.

Shaw, T.J., Francois, R., 1991. A fast and sensitive ICP-MS assay for the determination of $230 \mathrm{Th}$ in marine sediments. Geochimica et Cosmochimica Acta 55 (7), 2075-2078.
Shen, C.-C., Lawrence Edwards, R., Cheng, H., Dorale, J.A., Thomas, R.B., Bradley Moran, S., Weinstein, S.E., Edmonds, H.N., 2002. Uranium and thorium isotopic and concentration measurements by magnetic sector inductively coupled plasma mass spectrometry. Chemical Geology 185 (3-4), 165-178.

Shen, C.-C., Li, K.-S., Sieh, K., Natawidjaja, D., Cheng, H., Wang, X., Edwards, R.L., Lam, D.D., Hsieh, Y.-T., Fan, T.-Y., Meltzner, A.J., Taylor, F.W., Quinn, T.M. Chiang, H.-W., Kilbourne, K.H., 2008. Variation of initial ${ }^{230} \mathrm{Th} /{ }^{232} \mathrm{Th}$ and limits of high precision U-Th dating of shallow-water corals. Geochimica et Cosmochimica Acta 72 (17), 4201-4223.

Shen, C.C., Lin., H.T. Chu, M.F, Yu, E.F., Wang, X., Dorale, J.A., 2006. Measurements of natural uranium concentration and isotopic composition with permil-level precision by inductively coupled plasma-quadrupole mass spectrometry. Geochemistry Geophysics Geosystems 7, Q09005. doi:10.1029/2006GC001303.

Solari, L.A., Gomez-Tuena, A., Bernal, J.P., Perez-Arvizu, O., Tanner, M., 2010. U-Pb zircon geochronology with an integrated LA-ICP-MS microanalytical workstation: achievements in precision and accuracy. Geostandards and Geoanalytical Research 34 (1), 5-18.

Stirling, C.H., Andersen, M.B., Potter, E.-K., Halliday, A.N., 2007. Low-temperature isotopic fractionation of uranium. Earth and Planetary Science Letters 264 (1-2), 208-225.

Stirling, C.H., Esat, T.M., Lambeck, K., McCulloch, M.T., 1998. Timing and duration of the last interglacial; evidence for a restricted interval of widespread coral reef growth. Earth and Planetary Science Letters 160 (3-4), 745-762.

Stirling, C.H., Esat, T.M., Lambeck, K., McCulloch, M.T., Blake, S.G., Lee, D.C., Halliday, A.N., 2001. Orbital forcing of the marine isotope stage 9 interglacial. Science 291 (5502), 290-293.

Stirling, C.H., Esat, T.M., McCulloch, M.T., Lambeck, K., 1995. High-precision U-series dating of corals from Western Australia and implications for the timing and duration of the last interglacial. Earth and Planetary Science Letters 135 (1-4), 115-130.

Vanhaecke, F., de Wannemacker, G., Balcaen, L., Moens, L., 2003. The use of dynamic reaction cell ICP mass spectrometry to facilitate $\mathrm{Rb}-\mathrm{Sr}$ age determination. Special Publications, London. In: Vance, D., Müller, W., Villa, I. (Eds.), Geochronology: Linking the Isotopic Record with Petrology and Textures. Geological Society, London, pp. 173-181.

Weyer, S., Anbar, A.D., Gerdes, A., Gordon, G.W., Algeo, T.J., Boyle, E.A., 2008. Natural fractionation of ${ }^{238} \mathrm{U} /{ }^{235} \mathrm{U}$. Geochimica et Cosmochimica Acta 72 (2), 345-359.

Zhao, J.-X., Yu, K.-f., Feng, Y.-X., 2009. High-precision ${ }^{238} U-{ }^{234} U-{ }^{230}$ Th disequilibrium dating of the recent past: a review. Quaternary Geochronology 4 (5), 423-433. 